\title{
A INOVAÇÃO E O SISTEMA DE FRANQUIA NA CONSTRUÇÃO CIVIL DE SALVADOR: O CASO DO PLANO 100
}

\author{
Rosana Muñoz \\ Rogério H. Quintella
}

\section{RESUMO}

O presente trabalho tem como objetivo estudar o sistema de franquia como difusor de inovações tecnológicas e organizacionais no processo produtivo de uma empresa de construção civil, no subsetor de edificações. Para atingir este objetivo, realizou-se um estudo de caso na Construtora Akyo Ltda., franqueada da Construtora Rossi Residencial com o Plano 100 de Habitação. Analisaram-se as inovações organizacionais e tecnológicas introduzidas pela franquia, tomando como base o processo tradicional executado pela empresa anteriormente; e o impacto causado na produtividade, através da comparação de índices obtidos com a franquia e índices da construção tradicional.

\section{ABSTRACT}

The present work is intended to analyze the franchise system's role on the promotion and diffusion of organizational and technological innovations in the productive process of a building firm (contractor). In order to do that, a case study was conducted in Akyo's "Plano 100", where were analyzed the technological and organizational innovations introduced by the franchise. The traditional process previously executed by the company was used for productivity comparison purposes.

\section{INTRODUÇÃO}

O cenário de intensa competitividade pelo qual as empresas vêm passando, reflexo do rápido processo de desenvolvimento tecnológico de produtos e processos, aliado à integração dos mercados mundiais, tem ocasionado profundas modificações nos sistemas produtivos. As empresas tentam ser diferentes entre si - para concorrer a fatias maiores do mercado -, ou se colocam em dia com a diferenciação alcançada por uma delas, para sobreviver no mercado. No primeiro caso, podem utilizar mecanismos de inovação tecnológica, seja através da aplicação do conhecimento obtido na pesquisa básica, pesquisa aplicada ou desenvolvida; da aquisição de conhecimentos já elaborados ou na forma de novos equipamentos, insumos ou componentes produtivos. No segundo caso, as empresas entram em um processo claro de imitação pela reprodução da inovação. É, portanto, no primeiro caso que a franquia é abordada, uma vez que esta representa uma ação propulsora e difusora da introdução de inovações tecnológicas e organizacionais.

Diante do paradoxo entre a importância da indústria da construção civil para a economia nacional e seu estigma de "atraso" administrativo e tecnológico, o presente trabalho objetiva estudar a franquia na construção civil, e mais precisamente no subsetor de edificações, procurando mostrar, através de um estudo de caso - a franquia do Plano 100 de Habitação - a relação entre a introdução de inovações tecnológicas e organizacionais, através desse novo sistema, e a produtividade do trabalho.

Por ser a primeira, e aparentemente única, empresa franqueada em Salvador a atuar no subsetor de edificações, a Construtora Akyo Ltda., foi escolhida para o desenvolvimento deste trabalho. De 1994 a 2000, a empresa foi franqueada da Construtora Rossi Residencial, de São 
Paulo, com o Plano 100 de Habitação, introduzido com os objetivos de atender a classe média e de reduzir o desperdício e aumentar a produtividade da empresa, tornando-a mais competitiva $^{1}$ no mercado.

Segundo Prokopenko (1989), em uma definição geral, a produtividade é a relação entre a produção obtida por um sistema de produção ou serviços e os recursos utilizados para obtê-la. Assim, a produtividade se conceitua como o uso eficiente de recursos - trabalho, capital, terra, materiais, energia, informação - na produção de diversos bens e serviços. Uma maior produtividade significa obter mais com a mesma quantidade de recursos, ou a obtenção de uma maior produção em volume e qualidade com o mesmo insumo.

A produtividade também pode ser definida como a relação entre os resultados e o tempo que se leva para consegui-los. Assim, quanto menor tempo se usa para obter o resultado desejado, mais produtivo é o sistema (Prokopenko, 1989). É este o conceito de produtividade que é mais usado na Construção Civil.

\section{O CONTEXTO DA CONSTRUÇÃO CIVIL NO BRASIL E NA BAHIA}

No Brasil, a indústria de construção civil representa um dos maiores segmentos industriais da economia. Em 1990, a indústria foi responsável pela geração de 8,06\% do Produto Interno Bruto (PIB) brasileiro e 19,22\% do PIB industrial. Em 1995, a contribuição da indústria de construção civil para a formação do PIB industrial chegou a quase $24 \%$. A importância da indústria é ainda maior quando se refere à geração de emprego. De acordo com dados do Instituto Brasileiro de Geografia e Estatística - IBGE, um quarto dos empregos da indústria de transformação no Brasil foram gerados pela construção civil, em 1990. Embora possa se observar uma redução do nível de emprego desde então, o mesmo acontecendo em termos da indústria em geral, a participação relativa do emprego na construção, em relação ao emprego industrial do Brasil, ainda foi muito significativa em 1993 atingindo 24,44\% (Quintella \& Loiola, 1998).

$\mathrm{Na}$ Bahia, dados da SEI - Superintendência de Estudos Econômicos e Sociais da Bahia (2000) - indicam que em 1998 essa indústria foi responsável por gerar 12,1\% do PIB estadual e empregar, em média, 7\% do total de trabalhadores. Em termos de Nordeste, esses indicadores são mais expressivos. Com base em dados de 1997, Quintella e Loiola (1998) verificaram que na Bahia estão localizadas quase $20 \%$ das empresas nordestinas de construção civil e mais de $40 \%$ do total de empregos do setor. Pode-se observar que a indústria apresenta grande importância na matriz produtiva baiana, sobretudo, por sua capacidade de gerar emprego. Trata-se, portanto, de um segmento industrial prioritário em projetos de aceleração do desenvolvimento do Estado da Bahia.

O Sindicato da Indústria da Construção Civil da Bahia, SINDUSCON-BA, propõe a estratificação da indústria da construção civil em sete subsegmentos: Edificações em Geral, Incorporação Imobiliária, Saneamento, Energia e Telecomunicações, Terra e Pavimentação, Instalações e Montagens e Obras Públicas de Habitação. O subsetor de Edificações em Geral, no qual se concentra o estudo, se encarrega da construção de empreendimentos comerciais, residenciais, industriais e institucionais, seja no seu todo ou em partes dele, e tem sido caracterizado como conservador, tradicional e mal gerenciado. É freqüentemente mencionado como portador do estigma de "atrasado" (Farah, 1996; Oliveira, 1998).

O atraso tecnológico e organizacional na construção de edifícios no Brasil, segundo Farah (1996), caracteriza-se a partir dos seguintes aspectos: base manufatureira de produção;

\footnotetext{
${ }^{1}$ A competitividade deve ser entendida, segundo Coutinho e Ferraz (1994), como a capacidade da empresa de formular e implementar estratégias concorrenciais, que lhe permitam conservar, de forma duradoura, uma posição sustentável no mercado.
} 
baixa produtividade; alta incidência de patologias construtivas; desperdício de materiais; precárias condições de trabalho; e técnicas gerenciais ultrapassadas.

Em relação à base manufatureira de produção, embora haja certo grau de separação entre concepção e execução, o fundamento da atividade produtiva continua sendo a habilidade dos trabalhadores.

No que concerne à baixa produtividade, verifica-se que na construção de edifícios esta é normalmente calculada pelo índice de homem-hora por metro quadrado $\left(\mathrm{hh} / \mathrm{m}^{2}\right)$, resultado da divisão de toda mão-de-obra utilizada na construção pela área da mesma (Oliveira, 1998). Segundo Picchi (1993), o índice representativo da média brasileira é de $45 \mathrm{hh} / \mathrm{m}^{2}$. Para ele, este índice não reflete totalmente a realidade brasileira, uma vez que é obtido sobre o orçamento, não levando em consideração o retrabalho. Desta forma, ele estima que o índice correto deva ficar em torno de 70 e $80 \mathrm{hh} / \mathrm{m}^{2}$. Em alguns países obtêm-se índices entre 20 e 30 $\mathrm{hh} / \mathrm{m}^{2}$ com o uso da construção racionalizada, de 14 a $18 \mathrm{hh} / \mathrm{m}^{2}$ com o uso de pré-fabricação no local e de 8 a $12 \mathrm{hh} / \mathrm{m}^{2}$ com o uso de sistemas construtivos industrializados (Picchi, 1993). Percebe-se, portanto, que a produtividade na construção de edifícios, no país, está muito aquém dos níveis internacionais.

Ao lado destes fatores, o próprio caráter do produto o deixa sujeito às intempéries, provocando interferências no ritmo de trabalho, alterando a produtividade, interrompendo o andamento dos serviços, dificultando a programação da produção e as condições de trabalho.

Quanto a alta incidência de patologias construtivas, diversos tipos podem ser encontrados nas edificações, tais como: trincas, eflorescências, bolor, umidade, descolamentos e corrosão de armaduras. Segundo Oliveira (1998), não existem dados precisos quanto à incidência de patologias nos edifícios brasileiros, até porque os problemas são, em sua maioria, resolvidos pelos proprietários ou ocupantes das construções.

No que tange ao item desperdício de materiais, observa-se que a perda de materiais, cuja ocorrência deve-se não apenas ao transporte inadequado, mas a um conjunto maior de fatores, é bastante elevada. Estimava-se que cerca de $20 \%$ do material, em peso, era perdido sob a forma de entulho, sucata, sobras e material excedente. Na construção tradicional, os índices de perda costumavam ser ainda superiores aos usualmente considerados, atingindo, em obras, 33,11\% para o cimento e 39,02\% para a areia (Pinto, 1989).

Uma ampla pesquisa nacional ${ }^{2}$, realizada em canteiros de obras em todo o país, levantou as perdas de materiais dentro do canteiro de obras. O relatório final, apresentado em cinco volumes em 1998, mostrou que as perdas financeiras variam entre $3 \%$ e $8 \%$ do custo de construção, servindo para afastar eventuais mal-entendidos quanto a uma frase que se tornou comum ouvir, "de que se joga fora um prédio a cada três que se constróem" (Souza et alii, 1999).

As precárias condições de trabalho são manifestadas na desorganização do canteiro de obras, nas inadequadas instalações de alojamento e sanitários e no descaso quanto à segurança. Os trabalhadores da construção estão sujeitos a ação de diversos agentes físicos e químicos, tais como: calor, vibrações, ruídos, pressões elevadas, gases, poeiras, entre outros, que causam diversas doenças. $\mathrm{O}$ setor apresenta um dos mais elevados índices de acidentes de trabalho no país. Uma pesquisa realizada pelo Serviço Social da Indústria, SESI, constatou que, no ano de 1988, do total de trabalhadores acidentados no Brasil, 21,35\% eram operários da construção civil (Oliveira, 1998).

\footnotetext{
${ }^{2}$ Essa pesquisa foi coordenada pelo Departamento de Engenharia de Construção Civil da EPUSP (Escola Politécnica da Universidade de São Paulo) com a colaboração da FINEP (Financiadora de Estudos e Projetos) Programa Habitare, do SENAI (Serviço Nacional de Aprendizagem Industrial) - Projeto Estratégico Setorial da Construção, e a participação de universidades e construtoras brasileiras (nota dos autores).
} 
Aliados às impróprias condições de trabalho, os baixos salários e o término da obra são responsáveis pela alta rotatividade da mão-de-obra do setor, pois a permanência do operário confunde-se com a duração do serviço para o qual foi contratado, raramente possuindo um vínculo permanente com a construtora. Souza (1997) cita que vários estudos apontam um índice de rotatividade no setor cerca de três vezes superior ao verificado na indústria de transformação.

Em referência às técnicas gerenciais ultrapassadas, Farah (1996) observa que a construção civil ainda não incorporou o modelo taylorista-fordista, em que a gerência assume a responsabilidade pela concepção do trabalho, a programação e o controle das atividades. Pelo contrário, a definição de como executar o trabalho, a constituição de equipes, a programação e a alocação de tempos, o estabelecimento do ritmo de trabalho e o controle da produção se dão no interior das próprias equipes de produção, sob a liderança do mestre e do encarregado. $\mathrm{O}$ planejamento é pouco utilizado, havendo uma total desarticulação entre projeto e execução, e um limitado grau de programação do processo produtivo. Isto pode ser observado pela ocorrência freqüente de retrabalho e de paradas e esperas durante as atividades, e pelo grande volume de entulho e perdas. De acordo com Oliveira (1998), o planejamento e o controle de obras, segundo procedimentos formais, só foram adotados, na maioria dos casos, para atender a exigências dos agentes financiadores.

$\mathrm{Na}$ Bahia, um estudo realizado nas empresas de construção civil aponta como principais características de atraso do subsetor de edificações (Quintella \& Loiola, 1999): falta de padronização da produção; dificuldades de realizar planejamento no setor - relacionadas tanto a aspectos como falta de políticas estáveis para os diversos subsegmentos ou freqüentes mudanças nas regras do jogo pelo governo, quanto a aspectos mercadológicos; ausência de definição de estratégias de suprimento e de produto; falta de estratégia de treinamento de mão-de-obra; baixo nível de escolarização da mão-de-obra; elevados índices de desperdício e problemas de qualidade de produtos e serviços.

Empresários baianos falam sobre a ausência de políticas de fomento à competitividade empresarial como uma grande lacuna a ser superada. Além disso, indicam a inexistência de linhas de crédito especiais para as empresas do setor, a dificuldade de obtenção de crédito pelo consumidor, as altas taxas de juros e o elevado nível dos encargos sociais e dos impostos, como novos e importantes fatores que pressionam, negativamente, a organização da área (Quintella \& Loiola, 1999).

Como resultado da queda dos investimentos públicos em obras de infra-estrutura e dos investimentos privados no setor industrial, bem como a desarticulação do sistema financeiro de habitação, a indústria baiana vem atravessando uma grave crise. É expressivo o déficit habitacional baiano. Mudar este déficit passa, necessariamente, não apenas pela adoção de políticas governamentais, mas, também, pela melhoria do desempenho das empresas do setor, via incorporação de novas formas de produção e de modernos métodos administrativos e gerenciais. Neste cenário, aumento de qualidade e produtividade, assim como a redução de perdas, têm assumido crescente importância. Surge, então, a possibilidade de se adotar a franquia como um sistema de introdução de inovações organizacionais e tecnológicas para propiciar a conquista de condições sustentáveis de competitividade.

\section{O SISTEMA DE FRANQUIA}

O sistema de franquia ou simplesmente franquia $^{3}$ compreende a padronização de técnicas e métodos que dão a formatação de um negócio, ou seja, integram operacionalmente todas as atividades de uma empresa (Leite, 1991). Além destes termos, outra denominação muito utilizada é franchising, que, segundo Leite (1991), significa o ato de franquear ou, em

\footnotetext{
${ }^{3}$ Segundo Leite (1991), o termo franquia pode denominar o sistema como um todo.
} 
uma tradução literal, franqueamento; e que para Cherto (1988, p. 4) designa o sistema de forma genérica: "um método e um arranjo para a distribuição de produtos elou serviços".

Em uma abordagem econômica, Dahab e Loiola (1994, p. 293) definem franchising como "um modelo de organização da produção que se fundamenta em dois pilares básicos: uma marca consolidada, em cujo eixo se organiza todo o sistema, e uma vigorosa capacidade de gerar e difundir dentro de seus limites inovações tecnológicas e, sobretudo, organizacionais". Essa definição ressalta uma propriedade ímpar do sistema, e foco do estudo, que é a "vigorosa capacidade de gerar e difundir (...) inovações tecnológicas e (...) organizacionais".

O fundamento da técnica do sistema parte da filosofia que prega a união entre dois agentes - franqueador e franqueado, através de um contrato de franquia, e na transferência de recursos de uma empresa para outra. Este intercâmbio representa a base de sustentação para a viabilização da empresa franqueada (Dahab, 1996).

Segundo Dahab (1996), o sistema de franquia pode ser classificado em três dimensões, como mostrado no Quadro 1 a seguir.

\section{Quadro 1 - Classificação do sistema de franquia}

\begin{tabular}{|c|c|c|}
\hline $\begin{array}{c}\text { Quanto à forma de gestão } \\
\text { empresarial }\end{array}$ & $\begin{array}{c}\text { Quanto ao âmbito do } \\
\text { contrato }\end{array}$ & $\begin{array}{l}\text { Quanto à natureza do } \\
\text { franqueamento }\end{array}$ \\
\hline 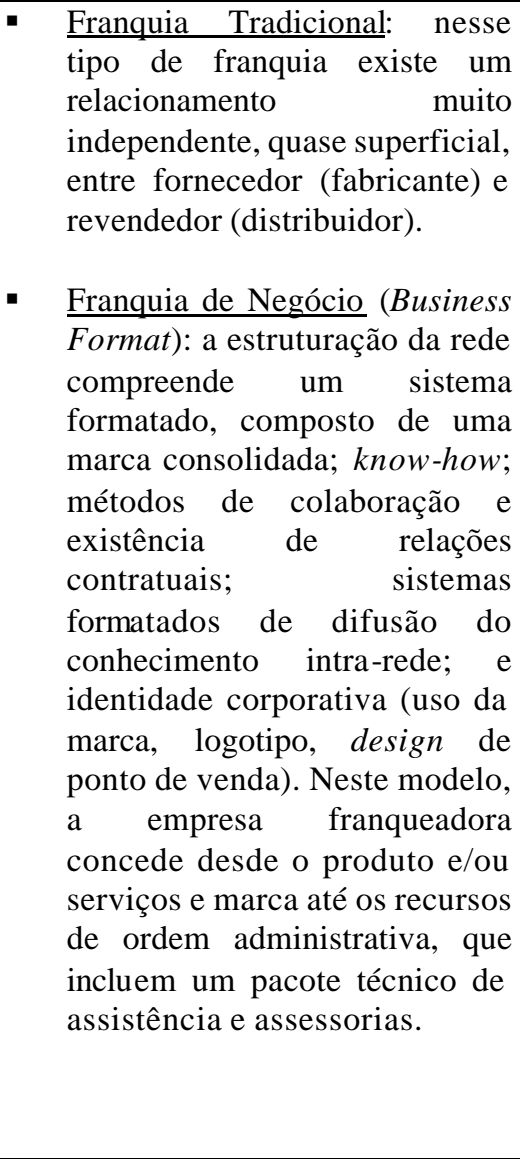 & 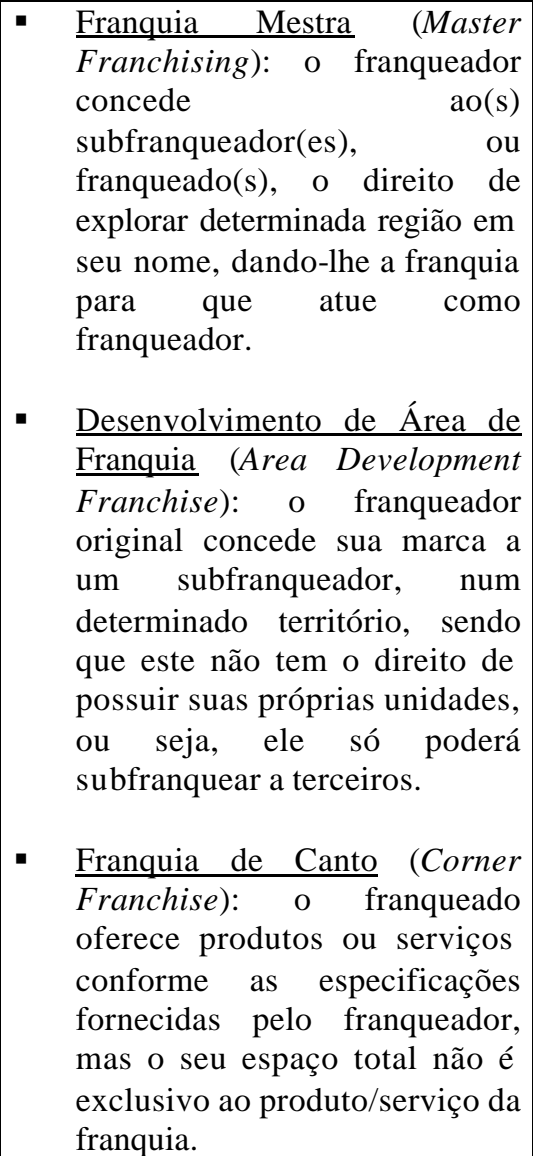 & 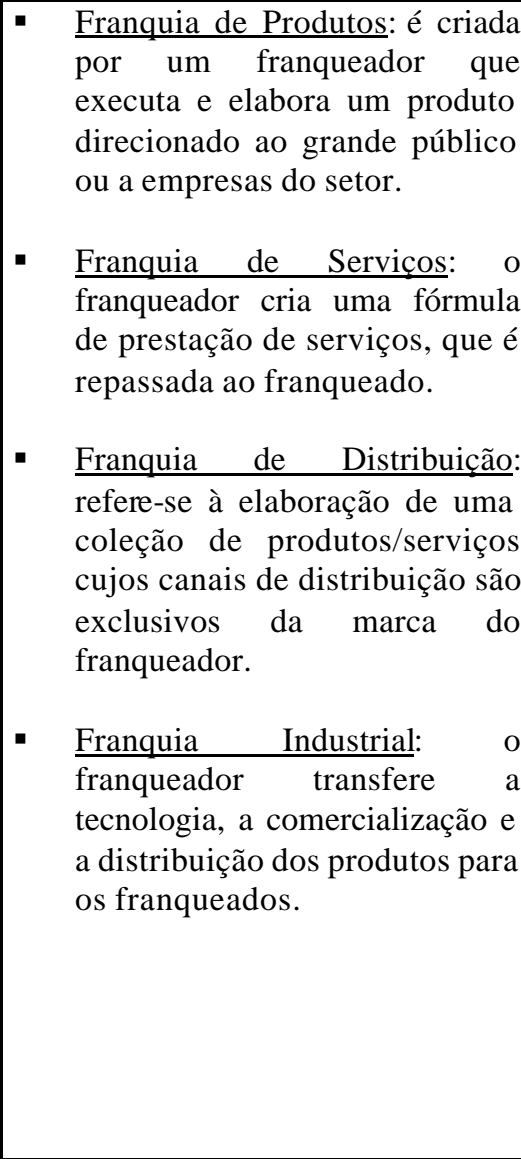 \\
\hline
\end{tabular}

Fonte: Adaptado de Dahab (1996, p. 17, 18 e 19).

O processo de formatação do sistema de franquia, segundo Pamplona (1999), pode ser caracterizado da seguinte maneira: a) Fase Inicial - compreende a análise dos elementos

\footnotetext{
${ }^{4}$ Esta dimensão define o escopo geográfico do contrato e as formas de hierarquização da relação franqueadorfranqueado, a partir da dimensão geográfica (Dahab, 1996).
} 
básicos à formatação; b) Fase Estrutural - consiste na formação geral do produto franquia; c) Fase Operacional - reúne composição dos manuais de operação e treinamento; d) Fase de Implementação - compreende a execução da lógica sequiencial da formatação; e) Fase de Reavaliação - engloba o ajuste do projeto e controle de qualidade da franquia.

Alguns aspectos financeiros envolvem a franquia (Pamplona, 1999): a) a taxa de franquia, que corresponde ao primeiro valor pago pelo franqueado ao franqueador na assinatura do contrato; b) a taxa periódica de franquia (royalties); c) a taxa de publicidade; e d) outras taxas, que representam o pagamento de serviços extraordinários, eventualmente prestados pelo franqueador.

Várias são as franquias nos diversos ramos de produtos e serviços no Brasil, por exemplo: cosméticos e perfumes, refeições rápidas, assistência técnica de eletrodomésticos, aluguel de veículos, entre outros. A franquia na construção civil é recente e mostra um crescimento cada vez maior. Segundo o guia oficial FRANQUIAS (1999), da Associação Brasileira de Franchising, o crescimento do segmento Decoração, Utilidades e Construção cresceu, em 1998, 10\%, em relação a 1997, ficando atrás apenas dos segmentos de Informática e Eletrônica, Limpeza e Conservação, ambos com 12 \%. Para o ano de 2003, em relação a 1999, a estimativa de crescimento é de 50\%, acompanhando a evolução de outros segmentos tais como Alimentação; Artigos Infantis; Impressão, Sinalização e Fotografia; e Informática e Eletrônica.

Diante do exposto, pode-se observar que o sistema de franquia tem apresentado uma tendência ao crescimento em vários segmentos. A certeza de que a franquia trará segurança e estabilidade ao crescimento das empresas franqueadas fundamenta-se no fato de que o sistema foi teorizado e testado empiricamente pela empresa franqueadora. Esta terá como respaldo o tempo de atuação em um determinado mercado e a exploração do mesmo (Pamplona, 1999). Por esta razão, alguns empresários vêem nas franquias a possibilidade de explorar diversos mercados de forma rápida, uma vez que o sistema, de certa forma, possui certo "sucesso" e reconhecimento.

Para analisar a dinâmica da franquia na construção civil como propulsora e difusora da introdução de inovações tecnológicas e organizacionais, foco deste estudo, faz-se, a seguir, uma revisão conceitual, onde se procura identificar os fundamentos teóricos da inovação, segundo a abordagem de Schumpeter e dos neo-schumpeterianos.

\section{A DINÂMICA INOVADORA DA FRANQUIA}

\section{A abordagem de Schumpeter}

Ao explicar o funcionamento da economia no capitalismo, Schumpeter (1961) parte de uma economia de fluxo circular em equilíbrio. A característica desse estado estacionário é que ele é um processo de contínua repetição, seja no campo da produção, seja no do consumo. A gestão da unidade produtiva se reduz a uma gestão da pura rotina, onde cada firma deve produzir sempre os mesmos tipos e as mesmas quantidades de bens, combinando, sempre do mesmo modo, os fatores necessários à produção.

Em seguida, Schumpeter introduz a inovação como elemento que rompe as rotinas do fluxo circular, e a aponta como causa do desenvolvimento econômico. Segundo Schumpeter (1961), o fenômeno fundamental do desenvolvimento capitalista é a capacidade de gerar e difundir inovações. Para o autor, as inovações caracterizam-se pela introdução de novas e mais eficientes combinações produtivas ou mudanças nas funções de produção, que constituem "o impulso fundamental que aciona e mantém em movimento a máquina capitalista" (1961, p. 60).

Segundo Schumpeter (1961), são cinco os tipos básicos de inovações:

- desenvolvimento de um novo bem, ou de uma nova qualidade de um bem já existente; 
- desenvolvimento de um novo método de produção, ou de uma nova logística comercial;

- desenvolvimento de um novo mercado;

- desenvolvimento de novas fontes de suprimento das matérias-primas ou produtos semi-industrializados;

- desenvolvimento de uma nova organização industrial, como a criação ou a fragmentação de uma posição de monopólio.

Partindo do referencial schumpeteriano, a franquia pode ser vista como uma inovação que introduz novas formas de produção. De uma forma geral, ela pode ser entendida como uma nova maneira de manejar comercialmente uma mercadoria, ou uma nova forma de obter produtos, serviços e tecnologias, além de proporcionar melhorias na rotina organizacional. Neste contexto, a franquia altera as atividades da empresa e introduz novos processos.

Schumpeter (1961) dedica pouco de seu esforço teórico na tentativa de estabelecer de que forma a inovação surge, isto é, de que forma é gerada dentro dos limites da firma. Assim, procurou-se buscar informações adicionais através de uma bibliografia que, baseada nos estudos de Schumpeter, abordasse de maneira ampla e dinâmica a inovação e o processo de difusão.

\section{A abordagem dos neo-schumpeterianos}

Os autores neo-schumpeterianos, segundo Possas (1989), estão basicamente compreendidos em dois grupos: um que faz uma abordagem "evolucionista", assim denominada por seus expoentes R. Nelson e S. Winter, da Universidade de Yale (EUA), e um mais novo, originário principalmente da Universidade de Sussex (UK), tendo como expoentes C. Freeman, C. Perez, K. Pavitt, L. Soete e G. Dosi, entre outros.

De forma geral, ambos os grupos analisam os processos de geração e difusão de novas tecnologias em sua natureza e impactos, destacando a inter-relação com a dinâmica industrial e a estrutura dos mercados. O critério metodológico utilizado é o desequilíbrio e a incerteza, o princípio teórico é a concorrência e o autor de referência é Schumpeter. O enfoque neoschumpeteriano não apenas se desdobra em direção à economia da mudança tecnológica, mas constitui o centro de sua análise, visto que, acompanhando Schumpeter, atribui à inovação o papel de principal dinamizador da atividade econômica capitalista (Possas, 1989).

Para Nelson e Winter (1982), a introdução de inovações estimularia as empresas à busca de métodos eficientes da produção. A inovação tecnológica seria o mecanismo de seleção para as firmas se manterem competitivas no mercado. Assim, as firmas que alcançariam sucesso no processo competitivo seriam aquelas cujas estratégias e rotinas organizacionais estariam mais ajustadas às mudanças do ambiente, além de mostrarem-se capazes de inovar.

Segundo Tidd et alii (1997), as mudanças das empresas podem ter duas formas - nas coisas (produtos/serviços) que uma organização oferta, e nas formas em que elas são criadas e entregues (processo). Existem, também, graus de inovações. Partindo-se do menor, têm-se os melhoramentos incrementais, e chegando-se ao maior, aparecem as mudanças radicais.

Castro (1999) esboçou uma classificação das inovações, baseada na disposição de Tidd et alii (1997), segundo seu impacto sobre o sistema econômico:

- Inovações incrementais, isto é, aperfeiçoamentos tecnológicos que ocorrem continuamente, resultado de atividades induzidas de $\mathrm{P} \& \mathrm{D}$, produto do trabalho dos departamentos de engenharia das empresas e sugestões dos usuários.

- Inovações radicais, constituídas de eventos descontínuos e que são resultado de trabalhos dirigidos de pesquisa e desenvolvimento.

- Revoluções tecnológicas ou inovações tecnológicas sistêmicas, que têm efeitos tão amplos que afetam a economia como um todo. 
Ainda em relação à inovação, Dosi, Nelson e Winter destacam a abordagem de paradigmas e trajetórias tecnológicas, que visam complementar e aprofundar o enfoque evolucionista. Os paradigmas tecnológicos representam os programas de pesquisa tecnológica, que se baseiam em modelos ou padrões de solução de problemas tecnológicos selecionados, e em boa medida pré-determinados, derivados de procedimentos igualmente selecionados.

O progresso técnico inerente a um determinado paradigma tecnológico é, então, denominado de trajetória tecnológica, e constitui o modo ou o padrão "normal" de realizar a formulação e solução de problemas específicos no interior daquele paradigma tecnológico. Assim, para Dosi (1988), os paradigmas são modelos para solucionar problemas tecnológicos selecionados, baseados em princípios científicos e tecnológicos; e as trajetórias, definidas pelo paradigma, indicam o "caminho", o sentido para o qual se orientam os processos de busca de inovações em relação a produtos, processos, organização da produção e administração.

A proposta teórica de Dosi (1990) também parte da noção de concorrência schumpeteriana e de seus desdobramentos para a análise da transformação e da dinâmica industrial, centrada nos padrões da mudança tecnológica, dando maior ênfase às assimetrias tecnológicas ${ }^{5}$ e produtivas como fatores cruciais na determinação de padrões da dinâmica industrial, que são geradas ou reforçadas essencialmente pela geração e difusão de inovações tecnológicas.

Dosi (1988) destaca o aprendizado como fundamental no processo de difusão das inovações, podendo ter três tipos de mecanismos:

a) o investimento em $P \& D$;

b) os processos informais de acumulação de conhecimento tecnológico dentro das firmas, como 'learning by doing' (aprender fazendo), 'learning by using' (aprender usando) e 'learning by interacting' (aprender interagindo);

c) o desenvolvimento de externalidades intra e interindustriais, que inclui difusão de informação, mobilidade de mão-de-obra especializada, e crescimento de serviços especializados.

Analisando o sistema de franquia segundo as abordagens apresentadas, pode-se observar que a formatação de um negócio no sistema de franchising pode ser considerada uma inovação radical, por parte dos franqueadores, em relação aos mecanismos tradicionais adotados pela maioria dos empresários; e as novas variações de produtos e/ou serviços oferecidos pela rede de franquia, já estruturada, podem ser consideradas inovações incrementais. Assim, uma vez estruturada a rede, o franqueador busca continuamente o aperfeiçoamento das rotinas executadas pelos franqueados, através da geração de inovações incrementais.

Quanto à difusão da inovação, esta se dá pela aprendizagem ${ }^{6}$ por parte dos franqueados, dado que o sistema é difundido totalmente padronizado pelo franqueador, seja em relação a produtos e/ou serviços e/ou processos produtivos. E essa tecnologia transferida aos franqueados incorpora tanto elementos tangíveis, como equipamentos e dispositivos, quanto intangíveis, como conhecimentos codificáveis ou não, know-how, métodos e experiência incorporados.

Deduz-se pelo enfoque de Dosi (1988/1990), que o franchising pode alterar as atividades da empresa e provocar assimetrias, na medida em que permite auferir maiores

\footnotetext{
5 Assimetrias tecnológicas são diferenças na capacidade tecnológica para inovar, nos distintos graus de sucesso na adoção e desenvolvimentos de inovações de produtos e de processos, e nas estruturas de custo (Dosi, 1990).

6 A aprendizagem pode ser definida, segundo Tigre (1998), como um processo no qual a repetição e a experimentação fazem com que, ao longo do tempo, as tarefas sejam efetuadas de forma mais rápida e melhor, e novas oportunidades operacionais sejam efetivamente experimentadas.
} 
lucros, dado a natureza do sistema de sobreviver mediante ganhos de escala, consolidação de marca, entre outras vantagens competitivas.

Ao formatar o sistema, o franqueador estabelece uma rotina aos franqueados, em função da sua experiência acumulada, mas mantém para si o know-how do sistema, que representa o resultado de um processo cumulativo de caráter original, e que the permite desenvolvê-lo e aperfeiçoá-lo, conservando, assim, o segredo tecnológico do sistema. Isto garante vantagens sobre os seus concorrentes, sustentando e ampliando as barreiras à entrada de novos franqueadores no mercado e mantendo os franqueados ligados a ele.

Pelo trabalho de desenvolvimento e coordenação das rotinas de operação executadas pelos franqueados, o franqueador recebe o pagamento de algumas taxas, como a taxa de franquia, de publicidade e os royalties. Em função disto, é fundamental que haja um intenso processo de busca de inovações incrementais por parte do franqueador, a fim de aperfeiçoar o sistema.

Ocorrendo em todos os setores produtivos, os processos de inovação e a posterior difusão apresentam características intrínsecas e graus diversos a depender do tipo de indústria e de fatores internos e externos às empresas. A seguir, aborda-se o processo de inovação nas empresas da indústria de construção civil.

\section{A INOVAÇÃO NA INDÚSTRIA DE CONSTRUÇÃO CIVIL}

Cardoso (1997), no que se refere à tecnologia produtiva, considera inovações tecnológicas as alterações introduzidas no processo de produção, tais que resultem no aumento do grau de industrialização desse processo, sendo que essas alterações podem ser basicamente de dois tipos:

- as que promovem o aumento do grau de racionalização, mecanização e pré-fabricação do processo tradicional, sem romper os limites de manufatura que o caracteriza;

- as que substituem o processo convencional, no todo ou em parte, por processos e sistemas considerados de alto grau de industrialização.

Direcionando o termo "inovação tecnológica" para o campo da tecnologia de construção de edificações, pode-se adotar a seguinte definição, extraída do trabalho de Barros (1996, p.60) e citada por Sabbatini (1989):

"um novo produto, método, processo ou sistema construtivo introduzido no mercado, constitui-se em uma inovação tecnológica na construção de edifícios quando incorporar uma nova idéia e representar um sensível avanço na tecnologia existente em termos de: desempenho, qualidade ou custo do edifício, ou de uma de suas partes". Assim, a inovação tecnológica no processo de produção de edifícios é um aperfeiçoamento tecnológico, resultado de atividades de pesquisa e desenvolvimento internas ou externas à empresa, aplicado ao processo de produção do edifício, objetivando a melhoria de desempenho, qualidade ou custo do edifício ou de uma parte do mesmo (Barros, 1996).

Tatum (1986), a partir do estudo de inovações tecnológicas ocorridas em diversas empresas de construção civil, afirma que as mudanças quanto às exigências dos usuários e a competição vêm demandando a implantação de inovações tecnológicas.

Em seu trabalho, o autor identifica alguns fatores que influenciam na introdução de inovações, tais como: estrutura do mercado, tamanho da firma e estágio de desenvolvimento da mesma; características do produto e mercado; relação entre o produto e o processo de manufatura; líderes empreendedores; prioridades gerenciais. Por outro lado, também destaca que as empresas possuem barreiras à inovação, entre as quais cita: relutância ao investimento, risco da inovação, ciclicidade econômica e sazonal e o papel dos fornecedores, que não têm contribuído para o avanço tecnológico (Tatum, 1986). 
Para o autor, o uso de tecnologias "consistentes" e a diminuição da fatia de mercado indicam a necessidade do avanço tecnológico. São os níveis de progresso tecnológico em outros países e as vantagens resultantes do avanço tecnológico que fazem da tecnologia a "chave" para a competição por mercados. Desta forma, as construtoras devem estabelecer um plano de ação que propicie a introdução de inovações tecnológicas (Tatum, 1986).

Assim, a partir do momento em que a empresa passa a ter a informação sobre a existência das novas tecnologias poderá implantá-las em seu sistema produtivo. Se a decisão for pela implantação, iniciará, então, um processo que envolverá diversas etapas que permitirão à empresa ir "aprendendo as novas tecnologias", conhecendo as suas características e efetivamente utilizando-as em seus canteiros de obras.

Tatum (1987) propõe um modelo composto de algumas diretrizes que devem conduzir o processo de inovação tecnológica para empresas de construção civil, mostrado na Figura 1.

Figura 1 - Processo de inovação em empresas de construção

\begin{tabular}{|c|c|c|c|}
\hline \multirow{2}{*}{$\begin{array}{l}\text { RECONHECER } \\
\text { AS FORÇAS E } \\
\text { OPORTUNIDA- } \\
\text { DES PARA A } \\
\text { INOVAÇÃO }\end{array}$} & $\begin{array}{l}\text { CRIAR } \\
\text { PARA } \\
\text { INOVAÇÃO }\end{array}$ & \multirow{2}{*}{$\begin{array}{l}\text { PROPORCIO- } \\
\text { NAR NOVAS } \\
\text { TECNOLOGIAS } \\
\text { CONSTRUTI- } \\
\text { VAS }\end{array}$} & $\begin{array}{l}\text { EXPERIMEN- } \\
\text { TAR E } \\
\text { REFINAR }\end{array}$ \\
\hline & \multirow{2}{*}{$\begin{array}{l}\text { - visão gerencial } \\
\text { e compromisso } \\
\text { com a melhoria } \\
\text { - proporcionar os } \\
\text { recursos } \\
\text { necessários }\end{array}$} & & \multirow{3}{*}{$\begin{array}{l}\text { - experimentar } \\
\text { em campo e em } \\
\text { laboratório } \\
\text { - testar com } \\
\text { produtores } \\
\text { - testar em } \\
\text { projetos } \\
\text { - interagir e } \\
\text { refinar }\end{array}$} \\
\hline \multirow{3}{*}{$\begin{array}{l}\text { - mercado e } \\
\text { demanda } \\
\text { - identificação de } \\
\text { "nichos" } \\
\text { - exigências da } \\
\text { legislação } \\
\text { - novas } \\
\text { tecnologias } \\
\text { - visão } \\
\text { estratégica }\end{array}$} & & $\begin{array}{l}\text { - adotar, modificar } \\
\text { e adaptar } \\
\text { - melhoria } \\
\text { incremental } \\
\text { - desenvolvimento }\end{array}$ & \\
\hline & \multirow{2}{*}{$\begin{array}{l}\text { DESENVOL- } \\
\text { VIMENTO DAS } \\
\text { CAPACIDADES } \\
\text { NECESSÁRIAS }\end{array}$} & $\frac{\boldsymbol{c} \boldsymbol{v}}{\text { RECURSOS }}$ & \\
\hline & & \multirow{2}{*}{$\begin{array}{l}\text { - produtores de } \\
\text { ponta } \\
\text { - outras indústrias } \\
\text { - concorrentes } \\
\text { - proprietários } \\
\text { - C\&T }\end{array}$} & \multirow{2}{*}{$\begin{array}{l}\text { IMPLEMEN- } \\
\text { TAR } \\
\text { - desenvolver } \\
\text { vantagens } \\
\text { competitivas }\end{array}$} \\
\hline & $\begin{array}{l}\text { - abrir fronteiras } \\
\text { - espírito } \\
\text { empreendedor }\end{array}$ & & \\
\hline
\end{tabular}

Fonte: Tatum, C. B., 1987, p. 650 (tradução dos autores).

Analisando a proposição de Tatum (1987), fica claro que o processo de inovação tecnológica na indústria da construção é iniciado à medida em que existe algum tipo de impulso para a mudança, ou seja, "as forças e oportunidades para inovação", que compreendem: demanda de mercado, identificação de novos "nichos", exigências da legislação, novas tecnologias e visão estratégica sobre as prioridades.

A partir do momento em que o foco estratégico da empresa passa a ser a implantação de melhorias e inovações, estabelece-se a necessidade de viabilizar essa estratégia. Segundo Tatum (1987), essa etapa deve envolver atividades que resultem num ambiente propício à receptividade das inovações e que permitam o desenvolvimento das capacidades exigidas.

Tatum (1987) salienta que as tecnologias podem ter diferentes origens, dentre as quais, destaca: a adoção de tecnologias provenientes de fontes externas à empresa; a modificação e adaptação de tecnologias disponíveis na empresa; a promoção de melhorias incrementais nas tecnologias em uso; o desenvolvimento de novas tecnologias. As etapas específicas de 
desenvolvimento da nova tecnologia não precisam ocorrer no âmbito da empresa. Elas podem se dar em ambientes diferentes, como por exemplo, em universidades, institutos de pesquisa e desenvolvimento, em empresas de materiais, componentes e equipamentos, ou outras, colocando, assim, as tecnologias disponíveis.

A partir da disponibilidade tecnológica, três fases são fundamentais para o início do processo de implantação: a "identificação", ou busca de tecnologias "candidatas" à implantação; a "avaliação", e a "decisão sobre a adoção" (Tatum, 1987). A avaliação pode ser feita segundo os seguintes critérios: grau com que a inovação atende aos objetivos da empresa ou a estratégia do empreendimento; tempo disponível para a implantação das mudanças; período de retorno; economia nos custos frente aos métodos convencionais; dificuldade de implementação; impacto sobre a moral, qualidade e segurança; entre outros (Barros, 1996, citando Laborde \& Sanvido, 1984). Feita a avaliação, toma-se a decisão sobre a adoção.

Para Tatum (1987), tendo-se decidido que tecnologia empregar, elabora-se um planejamento para a utilização e o refino da nova tecnologia. A criação de elementos de infraestrutura para a posterior implementação, como, por exemplo, obtenção de recursos, treinamento e comunicação, deve ser, então, providenciada. Ocorre, então, a última etapa que consiste na difusão das novas tecnologias na empresa como um todo.

Diante do exposto, a seção seguinte trata de um processo de inovação na construção civil, através da análise do Plano 100 como difusor de inovações técnicas e organizacionais, além de estimulador de inovações incrementais e aperfeiçoamentos; resultando, para a empresa, em uma maior produtividade; e tornando-a, consequentemente, mais competitiva no mercado.

\section{A FRANQUIA NA CONSTRUÇÃO CIVIL: UMA ANÁLISE DO PLANO 100}

As empresas de construção civil têm recorrido à adoção de inovações para manteremse no mercado. Um exemplo, nesse sentido, é a introdução da sistemática da franquia, adotada pela Construtora Akyo, a primeira empresa a adquirir, em Salvador, uma franquia de construção civil: o Plano 100 de Habitação. A aquisição da franquia do Plano 100 foi uma estratégia da Construtora Akyo para obter maior participação de mercado ${ }^{7}$, e, dessa forma, aumentar o faturamento.

A empresa franqueada relata que o processo construtivo do Plano 100 objetiva viabilizar a ampliação dos ganhos de produtividade e escala e, consequentemente, a redução de custos e desperdício para a empresa. Para tanto, são necessárias as seguintes premissas:

a) seleção de terrenos que simplifiquem os requisitos tecnológicos da obra;

b) início da obra com todos os projetos prontos e compatibilizados, o que minimiza as necessidades de intervenção no campo;

c) foco no fluxo de materiais, no sentido de minimizá-lo;

d) maior utilização de equipamentos simples, mas que influenciem positivamente na obra;

e) gestão diferenciada de mão-de-obra, adequada ao processo produtivo;

f) planejamento para reduzir a necessidade de pessoal e de horas extras.

O Plano 100 é um plano de habitação destinado à classe média e composto de 100 parcelas $^{8}$, corrigidas pelo IGP-M (Índice Geral de Preços do Mercado), a partir do momento em que o comprador recebe as chaves. No ato do contrato são pagas oito parcelas, ao receber as chaves doze; e mensalmente mais oitenta parcelas, com financiamento direto pela construtora.

\footnotetext{
${ }^{7}$ A empresa identificou, através de pesquisas, que o público de classe média não possuía outras opções de compra (nota dos autores).

${ }^{8}$ As parcelas situavam-se em torno de $\mathrm{R} \$ 600$ a $\mathrm{R} \$ 800$, a depender da fachada e andar. A preços de janeiro de 2001, um apartamento custava entre $\mathrm{R} \$ 70.000$ e $\mathrm{R} \$ 90.000$ (nota dos autores).
} 
De acordo com a classificação de Dahab (1996), apresentada anteriormente, o Hano 100 é uma franquia de natureza industrial, pois a Rossi Residencial transferiu técnicas organizacionais e a tecnologia construtiva dos empreendimentos para a franqueada, a Construtora Akyo Ltda. Quanto à gestão empresarial, esta franquia, no entanto, apresenta características particulares e não pode ser totalmente caracterizada como uma típica franquia de negócio, uma vez que não possui total formatação e assistência e assessoria contínuas por parte da franqueadora. No que tange ao processo produtivo, depois de ter sido introduzido o modus operandi da franquia, a Construtora Akyo teve autonomia de produção, podendo decidir sobre a introdução de inovações incrementais executadas pela própria empresa. A empresa segue as normas e procedimentos básicos e contratuais, porém tem liberdade de introduzir alterações construtivas, desde que não venham a comprometer o contrato. Não há, por parte da Rossi Residencial, a fiscalização ou controle do processo produtivo, como em uma franquia totalmente formatada, seja pela dificuldade de se padronizar a execução dos edifícios, uma vez que cada obra possui características próprias e está submetida a fatores externos e, às vezes, imprevisíveis; seja pela impossibilidade de controlar todas as fases produtivas. A Akyo possui, ainda, a liberdade de estabelecimento de preço das parcelas e prazo de execução dos empreendimentos. A definição convencional de franquia pode ser aplicada apenas no aspecto comercial e de distribuição, já que todo o processo de vendas segue os procedimentos contratuais de franquia.

Basicamente, a Akyo seguiu o que revelam as diretrizes propostas por Tatum, descritas anteriormente. Inicialmente, a partir da verificação do "nicho" de mercado, a Akyo passou pela seleção da origem das inovações, através da observação das fontes disponíveis, tais como publicações, incluindo livros e manuais; feiras e congressos; empresas de consultoria. Para a empresa, apesar de algumas técnicas já estarem publicadas, não havia quem as tivesse testado e posto em prática, indicando os resultados. Introduzir um novo conceito nessa área seria muito difícil, pois além de envolver muitas pessoas (operários, encarregados, mestres, engenheiros), demandaria tempo para a implantação. A fonte escolhida foi então o sistema de franquia.

Após as etapas de busca, identificação, avaliação e decisão da fonte de tecnologia, a empresa começou a implantação das inovações através do sistema de franquia. Durante a fase de implementação, ocorreu a difusão das inovações entre a Rossi e a Akyo, que compreendeu a transferência de tecnologia. Para viabilizá-la, foi necessário um treinamento através do SENAI - Serviço Nacional de Aprendizagem Industrial, além de visitas às obras de São Paulo, assessoria da Rossi em Salvador e todo um projeto de infra-estrutura para a implantação da franquia, que compreendeu a aquisição de novos equipamentos, materiais e mão-de-obra, resultando na operacionalização. Esta etapa durou poucos meses, dado que o sistema é difundido totalmente padronizado pelo franqueador.

A absorção da tecnologia ocorreu através do processo de aprendizado, que, de acordo com a abordagem de Dosi, este se deu, para a franqueadora - a Rossi Residencial -, com o desenvolvimento do sistema e suas operações, que corresponde ao 'learning by doing', à medida que a inovação é reproduzida; e, para a franqueada, ou seja a Akyo, com a operação do sistema ao longo do tempo, que corresponde ao 'learning by using', ou seja, aprender usando a inovação, auxiliado pelo treinamento. Além disso, o franchising implica em um aprendizado baseado na interdependência entre as partes, que corresponde ao 'learning by interacting', ou seja, aprender interagindo, através de um processo contínuo de busca de inovações incrementais.

Cardoso (1997), analisando o Plano 100, observou uma nova concepção de produção técnico-financeiro-comercial, através da qual a franqueada conseguia criar um mecanismo de produção com características industriais, mesmo que incipientes, e que conservavam os 
métodos de construção tradicionais, associados a uma série de medidas comerciais e financeiras essenciais.

$\mathrm{O}$ enfoque comercial do plano baseou-se na necessidade de se criar um produto ao mesmo tempo atrativo e barato. Estando escolhidos o público alvo e a base da padronização, a Rossi determinou as características essenciais do produto pelas quais os clientes estavam dispostos a pagar, definindo, desta forma, a satisfação do cliente como um de seus objetivos, e todo o sistema mercadológico.

Por sua vez, o enfoque financeiro levou à criação de mecanismos de autofinanciamento com características específicas, que conciliavam a capacidade de pagamento dos compradores com as necessidades de caixa das obras: preço pago em 100 parcelas; definição de empreendimentos padronizados e com tamanho mínimo (em média quatro torres de nove andares e 36 apartamentos cada); duração média dos canteiros de 36 meses; e o recebimento de, em média, ao menos $56 \%$ do valor de venda antes da entrega das chaves.

Por fim, o enfoque técnico, que levou à aplicação de formas de racionalização da produção particulares. Alguns aspectos podem ser citados: sincronização da execução no tempo; redução da variedade devido à padronização; parcerias com os industriais fornecedores; e melhoria técnica dos métodos tradicionais de execução. Assim sendo, a franquia do Plano 100 propiciou a introdução de inovações na empresa, alterando a forma de construir considerada, até então, como tradicional.

As inovações introduzidas com a franquia foram implantadas nos campos tecnológico (técnico) e organizacional (incluindo aspectos financeiros e comerciais). Através de entrevistas semi-estruturadas com o engenheiro responsável pela implantação do Plano 100, foram levantadas as inovações tecnológicas, identificadas em relação ao que a construtora utilizava antes ${ }^{9}$ da introdução do Plano 100. O Quadro 2, a seguir, mostra as inovações em termos de materiais.

\section{Quadro 2 - Materiais introduzidos através do Plano 100}

\begin{tabular}{|c|c|c|c|}
\hline $\begin{array}{l}\text { MATERIAIS } \\
\text { DEPOIS DO } \\
\text { PLANO }\end{array}$ & UTILIZAÇÃO & ANTES DO PLANO 100 & $\begin{array}{c}\text { VANTAGENS DOS NOVOS } \\
\text { MATERIAIS }\end{array}$ \\
\hline $\begin{array}{l}\text { Bloco de } \\
\text { concreto }\end{array}$ & Vedação & Bloco cerâmico & $\begin{array}{l}\text { Economia de revestimento, pela } \\
\text { regularidade de sua superfície. } \\
\text { Evita a quebra para colocação das } \\
\text { caixas, e o retrabalho. }\end{array}$ \\
\hline $\begin{array}{l}\text { Caixas } \\
\text { embutidas } \\
\text { nos blocos }\end{array}$ & $\begin{array}{l}\text { Pontos de } \\
\text { força e água }\end{array}$ & $\begin{array}{l}\text { Quebra da alvenaria pronta- } \\
\text { oara colocação das caixas e } \\
\text { oosterior recomposição }\end{array}$ & Reduz desperdício e retrabalho. \\
\hline
\end{tabular}

Fonte: dados fornecidos pela Construtora Akyo Ltda., 1999.

O Quadro 3, a seguir, mostra as inovações tecnológicas no processo produtivo, em termos de equipamentos.

\footnotetext{
${ }^{9}$ Alguns prédios para a classe média foram construídos de forma tradicional, antes do Plano 100: Sol Nascente, Jardim de Kyoto, Torre de Osaka, Torre Molinos, Pomar do Cabula (dados fornecidos pela Construtora Akyo Ltda.,2001).
} 


\section{Quadro 3 - Equipamentos introduzidos através do Plano 100}

\begin{tabular}{|c|c|c|c|}
\hline $\begin{array}{l}\text { EQUIPAMENTOS } \\
\text { DEPOIS DO PLANO }\end{array}$ & UTILIZAÇÃO & $\begin{array}{l}\text { ANTES DO } \\
\text { PLANO } 100\end{array}$ & VANTAGENS DOS NOVOS EQUIPAMENTOS \\
\hline - Nível a laser & - Nivelamento de pisos e paredes. & - Mangueira & - Maior precisão e rapidez. \\
\hline - Escantilhão & $\begin{array}{l}\text { - Manter a mesma espessura da argamassa, e as fiadas } \\
\text { niveladas. }\end{array}$ & - Linha e sarrafo $^{10}$ & - Maior precisão e rapidez. \\
\hline - Gabarito Pantográfico & - Regula a abertura de vãos, mantendo-a constante. & - Mestras ${ }^{11}$ e sarrafos & - Maior precisão e rapidez. \\
\hline - Jerica & $\begin{array}{l}\text { - Composta por um recipiente metálico fixado a um eixo } \\
\text { com duas rodas, é utilizada para transportar concreto. }\end{array}$ & - Carrinho-de-mão & $\begin{array}{l}\text { - Maior capacidade do que o carrinho-de-mão, facilidade, } \\
\text { rapidez e estabilidade no transporte. }\end{array}$ \\
\hline -Carrinho Argamasseiro & - Transporte de argamassa. & $\begin{array}{l}\text { Caixa } \text { de madeira } \\
\text { transportada pelo carrinho-de- } \\
\text { mão }\end{array}$ & $\begin{array}{l}\text { - Ao invés de trabalhar com a argamassa no chão, o } \\
\text { pedreiro trabalha em cima de um carrinho, numa altura } \\
\text { tal, que evita a realização de cerca de } 500 \text { movimentos de } \\
\text { flexão por dia, segundo a empresa. }\end{array}$ \\
\hline - Argamas seira de PVC & - Recipiente para o transporte de argamassa. & - Caixa de madeira & - Rapidez e facilidade no transporte. \\
\hline - Colher meia-cana & $\begin{array}{l}\text { - Colocação da argamassa no bloco. Compreende a } \\
\text { metade longitudinal de um tubo de pequena espessura } \\
\text { com uma alça. }\end{array}$ & - Colher de pedreiro & $\begin{array}{l}\text { - Rapidez e redução de desperdício. Com a utilização da } \\
\text { colher de pedreiro tradicional, } 50 \% \text { da argamassa caía no } \\
\text { furo do bloco e era desperdiçada. }\end{array}$ \\
\hline - Carrinho transportador & $\begin{array}{l}\text { - Transporte de blocos de concreto. Possui ganchos } \\
\text { inferiores para o transporte e empilhamento. }\end{array}$ & - Carrinho-de-mão & $\begin{array}{l}\text { - Não há contato humano com o bloco. A perda é quase } \\
\text { zero. }\end{array}$ \\
\hline - Cone metálico & $\begin{array}{l}\text { - Peça metálica, colocada na laje, com o objetivo de } \\
\text { deixar os furos para a passagem das tubulações verticais. }\end{array}$ & - Pedaços de madeira & $\begin{array}{l}\text { - Uniformidade do furo, reaproveitamento da forma e } \\
\text { facilidade e rapidez de execução. }\end{array}$ \\
\hline - Régua de tungstênio & $\begin{array}{l}\text { Alisa o concreto da laje, deixando a superfície } \\
\text { regularizada. }\end{array}$ & - Sarrafo e nível manual & - Maior precisão e rapidez. \\
\hline \begin{tabular}{|l} 
- Espaçadores de \\
armadura plásticos
\end{tabular} & - Dão o espaço entre a armação e a forma. & $\begin{array}{l}\text { - Espaçadores de argamassa ou } \\
\text { "rapaduras". }\end{array}$ & $\begin{array}{l}\text { - Não precisa imobilizar o pedreiro para fazer os } \\
\text { espaçadores de argamassa. }\end{array}$ \\
\hline
\end{tabular}

Fonte: dados fornecidos pela Construtora Akyo Ltda., 1999.

\footnotetext{
${ }_{10}^{10}$ Sarrafo é uma tira larga de tábua, utilizada como gabarito (nota dos autores).

${ }^{11}$ Mestra é um elemento de madeira ou outro material que é utilizado como referência de nível em uma edificação (nota dos autores).
} 
As inovações tecnológicas ocorreram na utilização de equipamentos e materiais e no processo construtivo, principalmente nas áreas de alvenaria e de estrutura, nos seguintes aspectos:

- Regularização da laje - após a concretagem, a laje fica pronta para receber o carpete ou outro tipo de revestimento. Não é preciso executar o contrapiso de regularização, como na construção tradicional.

- Acabamento na escada - foi introduzida, antes da concretagem, a colocação de uma cantoneira metálica na forma da escada, para a execução da quina do espelho do degrau, proporcionando a regularização da superfície para receber o revestimento. $\mathrm{Na}$ construção tradicional, após a concretagem, era aplicada uma argamassa de regularização, uma vez que as quinas se apresentavam irregulares, e só então é que se assentava o piso. A equipe do Plano 100 observou, na execução de cada pavimento tipo $^{12}$, que o metro quadrado da alvenaria, prevista para ser executada no centro da escada, representava um custo elevado. Assim, foi desenvolvido, pela Akyo, um caixão pré-moldado que é colocado com a estrutura, eliminando, desta forma, a alvenaria.

- Utilização de massa única - o revestimento da fachada não compreende as etapas tradicionais anteriormente desenvolvidas pela construtora: chapisco, emboço e reboco. Em função da planicidade da superfície do bloco de concreto, que proporciona a "queima" de etapas de revestimento, trabalha-se apenas com uma camada de massa única. Assim, externamente, as etapas são: chapisco, massa única, seladora e permalit $^{13}$ (revestimento que absorve qualquer imperfeição na esquadria); e, internamente, gesso e pintura. Os benefícios da redução de etapas são observados no aumento da produtividade.

- Utilização de shaft ${ }^{14}$ - em vez de quebrar a parede verticalmente para a passagem da tubulação hidráulica, como executado anteriormente, a alvenaria é interrompida para passagem da tubulação, que é coberta com placas pré-moldadas. No que se refere a tubulações de diâmetros menores, tais como a tubulação elétrica, a utilização dos blocos de concreto permite a passagem dos tubos internamente, pois possuem furos internos. Isto evita o desperdício e o retrabalho, porque não há necessidade de recompor a alvenaria quebrada como no processo tradicional.

Outras inovações, realizadas pela franqueada baiana, foram desenvolvidas. As principais inovações incrementais foram:

- Desenvolvimento de contramarcos em concreto pré-moldado, em substituição da verga $^{15}$ e contraverga.

- Paginação de blocos e cerâmicas de piso e parede - os engenheiros desenvolveram todas as vistas das paredes para tornar fácil, ao pedreiro, o assentamento de blocos e cerâmicas. Isto proporciona uma maior rapidez, uma vez que mediante o projeto de colocação de blocos, por exemplo, o pedreiro sabe onde deve colocar o bloco inteiro $(9 \times 19 \times 39)^{16}$, o meio bloco $(9 \times 19 \times 19)$ e aqueles que possuem as caixas embutidas.

\footnotetext{
12 Pavimento tipo é o pavimento de apartamentos que se repete ao longo da edificação (nota dos autores).

${ }^{13} \mathrm{O}$ permalit é um tipo de revestimento texturizado, de tecnologia italiana, que pode ser encontrado em diversas cores (nota dos autores).

${ }^{14} \mathrm{O}$ shaft é uma interrupção ou abertura da estrutura ou alvenaria para passagem de tubulações verticais, coberta, posteriormente, com placas pré-moldadas, de fibra de vidro, ou outros materiais (nota dos autores).

${ }^{5}$ Verga é uma peça de concreto que se coloca horizontalmente sobre "ombreiras" de portas ou de janelas (nota dos autores).

16 A primeira dimensão refere-se à espessura do bloco, a segunda à altura, e a terceira ao comprimento. Essas dimensões são padronizadas e foram as utilizadas pela Akyo, cabendo ressaltar que existem blocos de cimento de outras dimensões (nota dos autores).
} 
Hoje, a Rossi Residencial faz o mesmo em função desta inovação executada pela Akyo (ocorreu o processo de aprendizado 'learning by interacting', ou seja, aprendizado por interação, entre franqueador e franqueado). Em função da paginação executada, trabalha-se com a cerâmica de maneira a não ter nenhum arremate, tanto para revestimento de parede quanto de piso. Também, não há corte de blocos.

- Desenvolvimento de outros pré-moldados, tais como: caixas de incêndio, quadros de distribuição (quadros de luz) e caixas de gás. Normalmente, os padrões que se acham no mercado não acompanham a paginação do bloco. Desta forma, as caixas prémoldadas, por terem as medidas de paginação do bloco, evitam as quebras e o retrabalho.

Além das inovações na área técnica, o Plano 100 introduziu inovações na área organizacional. $\mathrm{Na}$ parte comercial, diversos aspectos de venda e publicidade foram introduzidos pela franquia, determinando a propaganda a ser feita, o design do produto, os padrões dos stands de vendas, os folhetos, o apoio ao consumidor e o processo de venda, que consistia em passar um vídeo com as explicações do plano, levar o interessado a conhecer o terreno, mostrar o apartamento decorado, e, finalmente, convencê-lo a comprar o apartamento.

A importância do componente comercial fica evidente. De fato, ao se munir de um conjunto bastante rico de informações de marketing, obtidas a partir de pesquisas de mercado, o produto-edifício possuía como pontos positivos principais, segundo a Akyo, o preço, os acabamentos oferecidos e as condições de pagamento. A porcentagem e a velocidade inicial das vendas comprovavam o "sucesso" comercial da idéia, que acabou sendo "copiada" por um grande número de concorrentes.

Outras inovações organizacionais introduzidas pelo Plano 100:

- Sistema de compras cooperadas.

A Construtora Akyo participa de uma rede, na qual todas as empresas nacionais envolvidas na franquia se utilizam dos mesmos insumos, provenientes dos mesmos fornecedores $^{17}$, o que acarreta um aumento das quantidades solicitadas e viabiliza o sistema de compras através da política de preços favoráveis à rede, proporcionada pelo maior poder de barganha.

- Planejamento das etapas das obras.

A ausência de coordenação entre projeto e execução, decorrente da dissociação entre concepção do produto (edificações e suas partes) e concepção do processo produtivo era uma característica das obras antes do Plano 100. Os projetos limitavam-se a definir características dos produtos, não considerando a fase de execução. Isto requeria que o projeto fosse adaptado, o que era feito, em boa parte, pelos trabalhadores no canteiro de obras. Esta adaptação tampouco era prevista como uma das atividades da obra, implicando também em paradas e esperas, e retrabalho.

O Plano 100 propiciou um melhor planejamento das obras, através da introdução do CPP, Controle do Processo Produtivo, formulário que indica o estágio que se encontra cada andar, proporcionando o planejamento da equipe, materiais e equipamentos a serem utilizados na próxima etapa, além de fornecer um meio de controle do andamento do andar. Antes da implantação do Plano 100, alguns problemas com o prazo de recebimento do concreto, por exemplo, desencadeavam erros de planejamento e a falta de controle implicava em atrasos.

\footnotetext{
17 Toda empresa franqueada do Plano 100, no Brasil, usa as mesmas especificações e tem os mesmos parceiros. Alguns exemplos são: tubulações, da Tigre; fechaduras, da LaFonte; elevadores, da Atlas; louças e metais, da Deca; cerâmicas de revestimento, da Portobello, entre outros (nota dos autores).
} 
No que se refere à área financeira, é provável que uma das principais vantagens do Plano 100 tenha sido o custo financeiro reduzido que ele oferecia aos compradores. Além disso, a venda se fazia diretamente entre a empresa e o comprador, sem intermediários. Segundo Cardoso (1997), a Rossi divulgava que comprar através do Plano 100 custaria $65 \%$ mais barato do que através de um financiamento do Sistema Financeiro de Habitação em 20 anos.

Além do financiamento direto na empresa e do número de prestações, 100 parcelas, o que propiciava a quitação do apartamento em até sete anos, outra inovação relatada foi a nova sistemática de custeio das obras no sistema condominial, através do qual busca-se dar ao cliente a possibilidade de conhecer previamente os seus desembolsos.

Diante do exposto, observa-se que a franquia do Plano 100 introduziu inovações no processo produtivo e administrativo, quando comparado ao que era realizado de forma tradicional, seja através da imitação de técnicas construtivas desenvolvidas pela Rossi Residencial ou através da execução de procedimentos e normas existentes nos manuais, seja pelas inovações incrementais desenvolvidas. Essas inovações fizeram com que a construtora aumentasse a produtividade e reduzisse o desperdício.

Para analisar os benefícios adquiridos com a franquia, quando comparada à construção tradicional, a Akyo calculou a produtividade do trabalho dos serviços considerados mais representativos, em relação ao custo, e fez comparações entre os obtidos na obra e os previamente considerados em orçamento.

Um dos índices mais importantes calculados pela Construtora Akyo Ltda. para avaliar a produtividade da mão-de-obra é o índice levante de alvenaria, que corresponde a quanto tempo o pedreiro gasta para fazer um metro quadrado de alvenaria. Outros índices também de grande importância são as produtividades referentes ao assentamento de cerâmica e execução de massa única, nas fachadas.

A seguir, apresenta-se a Tabela 1, em que são comparados os índices obtidos com o Plano 100 e os obtidos quando a Akyo construía de forma tradicional. Os dados do Plano 100 referem-se ao edifício Villa di Firenze, construído em 1999, e que, segundo a empresa, podem ser considerados representativos para todos os prédios, uma vez que a variabilidade é muito pequena, já que são utilizados a mesma equipe de mão-de-obra e, principalmente, os mesmos projetos. Os índices da construção tradicional são expressos pela média dos valores obtidos pela Construtora em outras obras, de mesmo porte, construídas anteriormente de forma tradicional.

\section{Tabela 1 - Índices de produtividade de alguns serviços}

\begin{tabular}{lcc}
\hline \multicolumn{1}{c}{ SERVIÇOS } & $\begin{array}{c}\text { ÍNDICE DE } \\
\text { PRODUTIVIDADE } \\
\text { DE OBRAS DO PLANO 100 } \\
\left(\mathrm{em} \mathrm{h} / \mathrm{horas}^{2} \mathrm{~m}^{2}\right.\end{array}$ & $\begin{array}{c}\text { ÍNDICE MÉDIO DA } \\
\text { CONSTRUÇÃO } \\
\text { TRADICIONAL } \\
\left(\mathrm{em} \mathrm{h} / \mathrm{horas}^{2} \mathrm{~m}^{2}\right)\end{array}$ \\
\hline $\begin{array}{l}\text { Levante de Alvenaria } \\
\text { Assentamento de cerâmica }\end{array}$ & 0,28 & 0,90 \\
Produção de massa única em fachada & 0,27 & 1,03 \\
- Chapisco & & 0,60 \\
- Massa única & 0,27 & 0,90 \\
\hline
\end{tabular}

Fonte: dados fornecidos pela Construtora Akyo Ltda. - 1999.

Quando comparados aos índices médios da construção tradicional, verifica-se que os índices de produtividade obtidos em obras do Plano 100 estão abaixo destes. Isto permite concluir que com a introdução das inovações no processo construtivo e de mudanças organizacionais houve um aumento da produtividade do trabalho. 
A franquia também permitiu que a Construtora Akyo Ltda. difundisse as inovações para suas outras obras e para a Construtora Suarez, empresa do grupo, que incorporou a tecnologia através de engenheiros multiplicadores, treinamentos e manuais da franquia. A difusão das inovações introduzidas pela franquia, no âmbito do mercado, se deu pela imitação, uma vez que as empresas que adotaram sistemas similares não apresentavam grandes assimetrias tecnológicas, tomando como referência a abordagem de Dosi. O processo de imitação se difundiu a partir da iniciativa de engenheiros que saíram da Akyo levando informações; de profissionais que observaram o processo construtivo ao longo do seu desenvolvimento; através de filmes, revistas e visitas. Empresas de consultoria também auxiliaram na difusão.

\section{CONSIDERAÇÕES FINAIS}

A inovação, seja de produtos ou processos, representa vantagens competitivas para as empresas, pois além de colocá-las no limiar do conhecimento, proporciona rápidas respostas à evolução e mudanças de mercado.

A maior utilização de equipamentos modernos e a adoção de novas formas de organização de produção e de técnicas modernas de gestão da qualidade parecem ser grandes preocupações das empresas de construção civil. As estratégias adotadas atualmente foram influenciadas, principalmente, pela retração no mercado das empresas dos diferentes subsetores, pela escassez de crédito, pelas exigências dos consumidores e pelas novas regulamentações públicas. Dentre as estratégias usadas pelas empresas, uma pode ser destacada: o sistema de franquia ou franchising, que proporciona um "atalho" para a introdução de inovações tecnológicas e organizacionais.

O Plano 100, foco do trabalho, foi estudado para avaliação da franquia como propulsora e difusora de inovações. Observou-se que o mesmo propiciou a introdução de inovações tecnológicas e organizacionais e o conseqüiente aumento de produtividade. As inovações introduzidas na empresa proporcionaram uma forte tendência à racionalização da produção, constituindo-se em um "caminho" para a possível industrialização, seja através da pré-fabricação, seja através da padronização. Essa trajetória tecnológica, de suma importância para a modernização do subsetor, tem sido perseguida por diversas empresas no país.

Apesar da Construtora Akyo Ltda. estar saindo do mercado de Salvador e do Plano 100 ter acabado, em função das dificuldades financeiras da empresa ${ }^{18}$, a franquia do Plano 100 propiciou uma alavancagem ao subsetor de edificações introduzindo inovações que permitiram aumentar a produtividade e diminuir o desperdício.

Urge, ainda, a necessidade de estudos complementares visando um maior aprofundamento a respeito do impacto da franquia na Construção Civil, especialmente no que tange a uma avaliação mais detalhada sobre o Plano 100.

Conclui-se, por fim, que a aquisição de novas tecnologias e a conseqüente qualificação da mão-de-obra são fundamentais para um desenvolvimento sustentado de uma indústria e de um país. É capacitando os agentes a absorver e aplicar as tecnologias a que tiverem acesso que se dará o processo de desenvolvimento e modernização do país.

\footnotetext{
18 As dificuldades financeiras ocorreram devido à transferência de recursos à holding Suarez, da qual a Construtora Akyo faz parte, aliada à relativa inadimplência dos compradores (dados fornecidos pela emp resa em Fevereiro de 2001).
} 


\section{REFERÊNCIAS BIBLIOGRÁFICAS}

BARROS, M. M. B. DE. Metodologia para implantação de tecnologias construtivas racionalizadas na produção de edifícios. Tese (Doutorado em Engenharia de Construção Civil e Urbana) - Escola Politécnica da Universidade de São Paulo, 1996.

CARDOSO, F. F. Estratégias empresariais e novas formas de racionalização da produção no setor de edificações no Brasil e na França. In: Estudos Econômicos da Construção, São Paulo, v. 2, n. 3, p. 119-160, 1997.

CASTRO, J. A. DE. Invento \& inovação tecnológica: produtos e patentes na construção. São Paulo: Annablume, 1999.

CHERTO, M. R. Franchising: revolução no marketing. São Paulo: McGraw-Hill, 1988.

COUTINHO, L. G.; FERRAZ, J. C. Estudo da competitividade da indústria brasileira. Campinas: Papirus, 1994.

DAHAB, S. S.; LOIOLA, E. Abordagem Schumpeteriana do Franchising: uma proposta de metodologia de pesquisa. In: Administração de Ciência e Tecnologia, v. 1, $18^{\circ}$ ENANPAD, Anais ... Curitiba, p. 291-304, 1994.

DAHAB, S. S. Entendendo Franchising. Salvador: CASA DA QUALIDADE, 1996.

DOSI, G. The Nature of Innovation Process. In: DOSI, G. et. alii. Technical Change and Economic Theory. London: Pinter Publishers, 1988.

Press, 1990.

Technical Change and Industrial Transformation. London: The Macmillan

FARAH, M. F. S. Processo de Trabalho na Construção Habitacional: Tradição e Mudança. São Paulo: ANNABLUME, 1996.

FRANQUIAS - Guia Oficial 1999. São Paulo: Associação Brasileira de Franchising (ABF) e Editora Empreendedor, 1999.

INSTITUTO BRASILEIRO DE GEOGRAFIA E ESTATÍSTICA - IBGE. Disponível na internet: http://www.ibge.gov.br, 2000.

LEITE, R. C. Franchising na criação de novos negócios. São Paulo: Atlas, 1991.

NELSON, R.; WINTER, S. G. An Evolutionary Theory of Economic Change. Cambridge: Harvard University Press, 1982.

OLIVEIRA, G. S. G. A Modernização da Construção Civil - subsetor edificações. In: TECBAHIA Revista Baiana de Tecnologia, Camaçari, v. 13, n. 1, p. 172-179, jan./abr. 1998.

PAMPLONA, C. A engenharia do franchising. Rio de Janeiro: Qualitymark, 1999.

PICCHI, F. A . Sistemas da qualidade: uso em empresas de construção de edifícios. Tese (Doutorado em Engenharia Civil) - Universidade de São Paulo, 1993.

PINTO, T. DE P. Perda de materiais em processos construtivos convencionais. São Carlos: UFSCAR, 1989.

POSSAS, M. L. Em direção a um paradigma microdinâmico: a abordagem neoschumpeteriana. In: Ensaio sobre Economia Política Moderna: teoria e história do pensamento econômico. Organização: Edward J. Amadeo. São Paulo: Editora Marco Zero, p. 157-177, 1989.

PROKOPENKO, J. La Gestion de la Productividad. Ginebra: Oficina Internacional del Trabajo, 1989.

QUINTEllA, R. H.; LOIOLA, E. Diagnóstico Competitivo da Indústria da Construção Civil. Salvador: IEL/NACIT - Escola de Administração da UFBA, 1998.

Administração Estratégica: O Caso das Empresas da Construção Civil na

Bahia. In Organizações \& Sociedade. Publicação da EAUFBA, Salvador, v. 6, n. 15, p. 3549, maio/ago. 1999.

SCHUMPETER, J. A.. Teoria do Desenvolvimento Econômico. Rio de Janeiro: Editora Fundo de Cultura S.A., 1961. 
SOUZA, F. A. P. DE. Organização da construção de edificações enfocando as filosofias e princípios da organização da produção. Dissertação (Mestrado em Engenharia de Produção) - Universidade Federal do Rio Grande do Sul, 1997.

SOUZA, U. E. L. DE; PALIARI, J. C.; AGOPYAN, V. O custo do desperdício de materiais nos canteiros de obras. In: QUALIDADE NA CONSTRUÇÃO, SINDUSCON-SP, ano 3, n 21, p. 64-66, 1999.

SUPERINTENDÊNCIA DE ESTUDOS ECONÔMICOS E SOCIAIS - SEI. Disponível na internet: http://www.sei.ba.gov.br/, 2000.

TATUM, C. B. Potencial Mechanisms for Construction. In: Journal of Construction Engineering and Management, v. 112, n. 2, p. 178-191, 1986.

Process of Innovation in Construction Firm. In: Journal of Construction Engineering and Management, v. 113, n. 4, p. 648-663, 1987.

TIDD, J.; BESSANT, J.; PAVITT, K. Managing innovation: integrating technological, market, and organizational change. West Sussex, England: John Wiley \& Sons Ltd., 1997.

TIGRE, P. B. Inovação e Teorias da Firma em Três Paradigmas. In: Revista de Economia Contemporânea, Rio de Janeiro, n. 3, p. 67-111, jan./jun.1998. 